\title{
The Vienna FES Interview Protocol - A mixed-methods protocol to elucidate the opinions of various individuals responsible for the provision of FES exercise
}

\author{
Matthew J. Taylor (1,2), Ché Fornusek (3), Andrew J. Ruys (1), Manfred Bijak (4), \\ Adrian E. Bauman $(2,5)$ \\ (1) Faculty of Engineering and IT, University of Sydney, Camperdown, Australia;(2) Charles \\ Perkins Centre, University of Sydney, Camperdown, Australia; (3) Faculty of Health Sciences, \\ University of Sydney, Lidcombe, Australia; (4) Centre for Medical Physics and Biomedical \\ Engineering, Medical University of Vienna, Vienna, Austria; (5) Sydney School of Public \\ Health, University of Sydney, Camperdown, Australia.
}

This article is distributed under the terms of the Creative Commons Attribution Noncommercial License (CC BY-NC 4.0) which permits any noncommercial use, distribution, and reproduction in any medium, provided the original author $(s)$ and source are credited.

\begin{abstract}
Functional Electrical Stimulation (FES) is the production of electrically elicited muscle contractions to perform a function or task. It has been used as a method to regain lost body functions or support weak body functions, and as such, has been clinically available since the early seventies. Some methods are applied routinely while others have not been translated to the bedside, or are still largely restricted to laboratory use. Progress in this field might be achieved by a strong cooperation of patients, clinicians, therapists and engineers. A better insight into multiple perspectives may help in understanding the shortcomings of current FES technology. This will help direct future research efforts into design of systems and potential application in relevant populations. In addition, these findings can assist with the translation of FES technology into a community context. We outline an interview protocol designed for use at the 12th Vienna International Workshop on Functional Electrical Stimulation where the mentioned experts from the field of FES met.
\end{abstract}

Key Words: qualitative, FES, interview

The method of Functional Electrical Stimulation (FES) has been well-known by participants of the triennial Vienna International Workshop on FES to have proven benefits on paralyzed muscle as can be measured by studies looking at physiological outcomes. There have been numerous studies examining such outcomes as muscle mass, ${ }^{1}$ joint torque as result of stimulation and bone mineral density. ${ }^{2}$ In addition, there have been international efforts into medical device innovation, such as that of the Medical University of Vienna group, researchers at the University of Sydney, Australia, ${ }^{3}$ and others. Furthermore, there are several international FES companies such as Schuhfried (Austria), BerkelBike (The Netherlands), Hasomed (Germany) and Restorative Therapies (United States) that develop FES systems for application in clinical populations. The BerkelBike is a good example of an FES system developed for community usage. With the versatility to be used both indoors and outdoors, as well as its' lightweight frame and simply adjusted seat height, it has been used by persons with spinal cord injury (SCI), multiple sclerosis (MS), cerebral palsy (CP) and brain injury for exercise. In addition, there are several other devices such as the hand-held Stiwell med 4 (Ottobock) and Parastep system that can be used for isometric muscle training and FES-walking, respectively. Despite these innovations, there is currently limited translation of these devices to community and home usage.

However, in light of all this research and development, there has been lesser attention on the client-focused "qualitative" design. Qualitative research, may provide a more complete view of the "experiences" of participants, as suggested by Greenwood et al. ${ }^{4}$ in their study of stroke patients' carers. Despite an initial report by Sipski and colleagues in the late 1980s on patient perceptions of FES cycling, ${ }^{5}$ and the work of the Odstock group in patient perspectives of FES for footdrop, ${ }^{6}$ we believe there could be further perspectives not captured by these authors, implementing our qualitative design. The findings of our study will be used to further understand the perspectives of 
First Name:

Gender:

Age Group (please circle): $<20 \quad 20-29 \quad 30-39 \quad 40-49 \quad 50-59 \quad 60-69 \quad 70+$

Country of Residence:

Please circle which best describes your occupation:

- $\quad$ FES seller/retailer

- $\quad$ FES prescriber or researcher

- Neuromodulation engineer

- $\quad$ Other (please specify):

- Email address:

(optional - if you wish to receive summary of project when it is finished)

Fig 1. The demographic questionnaire. It was designed to encapsulate the basic characteristics of participants in a timely manner. Participants' perspectives may be compared later on a basis of these characteristics.

individuals involved with FES. These perspectives will add to the small body of literature in the area and influence further innovation in this field.

\section{Examples of different types of FES research}

Research can be characterized in three domains; quantitative, qualitative and mixed-methods.7Within the context of FES research, there are several examples of all forms of these studies. For example, use of nearinfrared spectroscopy (NIRS) has been used to examine oxygen consumption levels of muscle before and after a training period of FES cycling in individuals with multiple sclerosis. ${ }^{8}$ Qualitative methods have also been employed to explore people's opinions about FES, from the perspective of both individuals with SCI and medical professionals in the work of Donovan-Hall et al. ${ }^{9}$ Mixed-methods studies offer an advantage of combining both methodologies together, providing a greater scope for "understanding" of a given issue. ${ }^{7}$ In the context of FES research, mixed-methods designs may be used to gain a thorough understanding of the effects of FES on the individual. For example, the Edinburgh group conducted both analysis of gait (quantitative) and semi-structured interviews (qualitative), in their study of FES for foot drop in stroke. ${ }^{10}$ For the protocol discussed herein, we devised an interview study focused solely on the experiences of various groups involved with FES, whom were not patients themselves. It was a mixed-methods design in the sense that while it was focused on a qualitative methodology of interview questions, there was also a small quantitative component. Multiple instruments were also used, including; a demographic questionnaire, semi-structured interview schedule and short response questions.

\section{The Vienna FES Interview Protocol}

A protocol was developed to investigate the opinions of individuals responsible for the provision or research of FES for exercise in paralyzed populations, in attendance at the 12th Vienna International Workshop on FES, Austria, Sep 7-9, 2016. It was the first time such an activity was carried out at the workshop. While usually the workshop is focused on the presentation of original data, this was the first time the conference itself was used for the collection of research data of a qualitative nature. The purpose of the study was to add to the relatively small body of qualitative information in the current literature, which will be a focus of upcoming work that aims to present the results of this study. The protocol discussed in this communication is of a 3-part structure.

The research questions which this study aimed to address were as follows:

- What do FES providers and engineers conceive to be the preferred type(s) of FES technology that clients use, or would use, on a regular basis for exercise?

- How do the perceptions of biomedical engineers differ from that of FES providers who are involved with FES therapy (selling, prescribing, or recommending) for typical populations who would use it.

- What is the opinion of FES providers and engineers regarding self-use of FES for exercise? 
1. What are the issues surrounding daily use of FES for exercise in paralyzed populations?

2. Can you briefly outline your experience of FES with clients?

3. Who sells FES equipment in your country? Who tells people how to use it?

4. Do you think exercise adherence differs in a lab or clinic as opposed to a home environment? Why?

5. What do you think are some of the benefits of FES?

6. In your experience with FES therapy, what are the initial expectations of clients before starting FES exercise? Are their initial expectations met? Do they differ depending on when they start FES post-injury

7. What are some of the big unanswered questions in the field of FES?

Fig 2. Interview schedule. The interview was designed to be a smaller version of a larger Australian protocol, focusing on the most relevant questions to ask participants in a short period of time at the conference.

- How do people define functional electrical stimulation, and are there any common misconceptions?

- What do people think FES is used for, and how many people do they think use it for exercise?

- What is the perception of FES providers regarding who they think is responsible for instructing in the correct usage of FES?

- What are the perceived health benefits of FES, and how do the perspectives of FES providers match against literature?

- What are the opinions of FES providers regarding factors that contribute to exercise adherence in lab, clinic and home settings?

- What do FES providers see as being important unanswered questions in the field of FES?

- How do the perspectives of international FES experts regarding expectations from FES treatment compare against the currently available qualitative literature on FES? (e.g., Barrett \& Taylor). ${ }^{11}$

Herein we describe its format, while alluding to potential relevance of the findings of this study for the FES community.

\section{Section 1 - Demographic questionnaire}

The first section was a demographic questionnaire, used to capture characteristics such as age, gender and country of origin of participants (Figure 1). It was the only part-quantitative component. The questionnaire also asked participants to stipulate their occupation, which may be colloquially defined as "sellers" (FES seller/retailer), "providers" (FES prescriber/researcher) or "builders" (neuromodulation engineer). A category was also left for those participants who did not fit one or more of those categories. This grouping of participants is such that post-hoc comparisons of perspectives derived from section 2 may be drawn, across different occupational groups. These perspectives may be able to guide further innovation in this field, taking into account considerations from different angles.

\section{Section 2 - Semi-structured interview}

The second section was a semi-structured interview, designed to encapsulate the opinions of participants regarding FES for exercise in paralyzed populations. Such interviews are typically carried out by using a list of questions which give some direction to the interview, but at the same time individuals are given due time to expand further on any issues in which they may wish to digress from the questions. ${ }^{12-14}$ The questions were designed following a review of the literature. A similar semi-structured approach was adopted by the work of Shiels \& colleagues in their foot-drop study. ${ }^{10}$

The interview protocol was a truncated version of a larger instrument to be used for interviewing participants of the second part of this study in Australia. The purpose of this reduction in size was to facilitate a design that could be conducted in a time period of 10-15 minute timeslots at the conference. It was made to be concise, whilst focussing on the most relevant issues.

There were seven interview questions (Figure 2). Question 1 was a general enquiry regarding what issues conference participants could envisage may be faced in the daily use of FES by clients. This question is important in the context of device development. For example, Bates et al. assert that individuals will "accept" technologies if they can be used in a way they themselves desire. ${ }^{15}$ Elucidating, and addressing issues with current FES systems may help improve their uptake in the future. Questions 2 and 3 were more personal, focussing on the users' themselves and experience of FES within their country. Question 4 was aimed at investigating the differences between exercise frequency in the home as opposed to an environment where there is an external form of assistance readily available (laboratory or clinic setting). Question 5 was focussed on the perceived benefits of FES, from the perspective of participants. Question 6 was perhaps the 


\begin{tabular}{|l|l|l|}
\hline \multicolumn{1}{|c|}{ FES Modality } & Advantages & Disadvantages \\
\hline FES-cycling & & \\
\hline FES-walking & & \\
\hline FES-rowing & & \\
\hline FES-isometric & & \\
\hline FES-implantables & & \\
\hline & & \\
\hline
\end{tabular}

Fig 3. The table was designed to be very open-ended, with columns listing advantages and disadvantages.

most involved question, delving into expectations of FES from a client/patient perspective. Expectations are essential to understand in this field, and it was suggested by Bradley that work in this field is requisite as ones' expectations may relate to how suitable one is to partake in FES exercise. ${ }^{16}$ Moreover, the findings of our study will build on literature examining expectations of FES technologies to date, such as Guest et al. ${ }^{17}$ The final question 7 was aimed at investigating what questions are unanswered in the field, effectually probing the idea of where research could be aimed in the upcoming years.

\section{Section 3 - FES Table}

The final component of the study protocol was an openended table, listing several different modalities of FES exercise (Figure 3), with columns for participants to list advantages and disadvantages that they perceive with such technologies. The table included common forms of FES exercise, such as FES cycling, isometric electrical stimulation, and FES supported standing up, standing and stepping. Also included were newer forms of FES exercise: rowing, implantables and exoskeletons combined with FES technologies. The table listed these forms with general wording and as such, was open to various interpretations (Figure 3) as was seen at the conference.

\section{Intended outcomes, future directions, preliminary observations}

The data obtained from the application of this protocol may have several implications for the field of FES technology development and application. These include:

1. Following the EU RISE projects, ${ }^{18-25}$ the data obtained from participants may be used to further understand issues surrounding translation of FES for usage in the home, in concordance with question 4;

2. The perceived benefits of FES may differ from actual benefits; 


\section{The Vienna FES Interview Protocol}

Eur J Transl Myol 27 (3): 160-165

3. The final question 7 may be used to help direct future clinical studies of FES, that are aimed at elucidating answers to research questions that are still not understood well in this area;

4. Opinions of different types of FES exercise may be compared;

5. Perspectives of providers and researchers may be compared with those of patients themselves, which is the focus of other forthcoming work.

We hope that this protocol may be used to highlight some current issues with FES technology, and lead to a greater understanding of where future research efforts could be well-guided to pursue.

\section{List of acronyms}

CP - cerebral palsy

FES - functional electrical stimulation

MS - multiple sclerosis

SCI - spinal cord injury

\section{Author's contributions}

MJT drafted the manuscript and was responsible for literature review and study design, $\mathrm{AEB}$ and $\mathrm{CF}$ contributed to the study design, AEB, CF, MB, AJR, gave feedback on the manuscript, $\mathrm{MB}$ assisted with the organization of the study in Vienna and drafting of the manuscript.

\section{Acknowledgments}

MJT was supported by a Grants-in-Aid from the University of Sydney to attend the 12th Vienna International Workshop on FES, Vienna, Austria, 2016. He wish to acknowledge the helpful staff of the Medical University of Vienna, in particular Melitta Pichler who enabled this study to be eventually carried out at the 12th Vienna International Workshop on FES. In addition, he would like to thank Guy Wilson for pointing him in right direction with the exercise adherence idea.

\section{Conflict of Interest}

The authors state no conflict of interests.

\section{Corresponding Author}

Mr. Matthew James Taylor, Level 3 East, Charles Perkins Centre D17, The University of Sydney, NSW, 2006, Australia.

Phone: + 61286270521 Mobile: + 61478033859

E-mail: matthew.j.taylor@sydney.edu.au

\section{E-mails of co-authors}

Ché Fornusek: che.fornusek@ sydney.edu.au

Andrew J. Ruys: andrew.ruys@sydney.edu.au

Manfred Bijak: manfred.bijak@meduniwien.ac.at

Adrian E. Bauman: adrian.bauman@sydney.edu.au

\section{References}

1. Mahoney ET, Bickel CS, Elder C, et al. Changes in skeletal muscle size and glucose tolerance with electrically stimulated resistance training in subjects with chronic spinal cord injury. Arch Phys Med Rehabil 2005;86:1502-4.

2. Mohr T, Pødenphant, J, Biering-Sørensen, F, et al. Increased bone mineral density after prolonged electrically induced cycle training of paralyzed limbs in spinal cord injured man. Calcif Tissue Int 1997;61:22-5.

3. Fornusek C. An isokinetic functional electrical stimulation leg cycle ergometer for individuals with spinal cord injury. Doctor of Philosophy $(\mathrm{PhD})$ thesis, The University of Sydney, 2005.

4. Greenwood N, Mackenzie A, Cloud GC, Wilson $\mathrm{N}$. Informal primary carers of stroke survivors living at home - challenges, satisfactions and coping: A systematic review of qualitative studies. Disabil Rehabil 2009;31:337-51.

5. Sipski ML, Delisa JA, Schweer S. Functional electrical stimulation bicycle ergometry: patient perceptions. Am J Phys Med Rehabil 1989;68:1479.

6. Taylor PN, Burridge JH, Dunkerley AL, et al. Patients' perceptions of the Odstock Dropped FootStimulator (ODFS). Clin Rehabil 1999;13:439-46.

7. Creswell JW, ed. Research design: qualitative, quantitative, and mixed methods approaches. SAGE Publications, Inc.; 2014. Available from: https://au.sagepub.com/en-gb/oce/researchdesign/book237357.

8. Reynolds MA, McCully K, Burdett B, et al. Pilot study: evaluation of the effect of functional electrical stimulation cycling on muscle metabolismin nonambulatory people with multiple sclerosis. Arch Phys Med Rehabil 2015;96:627-32.

9. Donovan-Hall MK, Burridge J, Dibb B, et al. The views of people with spinal cord injury about the use of functional electrical stimulation. Artif Organs 2011;35(3):204-11.

10. Shiels J, Wilkie K, Salisbury L, et al. the establishment of a new Lothian Functional Electrical Stimulation Clinic - an evaluation and exploration [poster]. In: British Society of Rehabilitation Medicine Spring Meeting, 19-20 May 2008, Birmingham, UK.

11. Barrett C, Taylor P. The effects of the Odstock drop foot stimulator on perceived quality of life for people with stroke and multiple sclerosis. Neuromodulation 2010;13:58-64.

12. Haas BM, Price L, Freeman JA. Qualitative evaluation of a community peer support servicefor people with spinal cord injury. Spinal Cord 2013;51:295-9. 


\section{The Vienna FES Interview Protocol}

Eur J Transl Myol 27 (3): 160-165

13. Jannings W, Pryor J. The experiences and needs of persons with spinal cord injury who can walk. Disabil Rehabil 2012;34:1820-6.

14. Noyes J. Health and quality of life of ventilatordependent children. J Adv Nurs 2006;56:392-403.

15. Bates PS, Spencer JC, Young ME, Rintala DH. Assistive technology and the newly disabled adult: adaptation to wheelchair use. Am J OccupTher 1993;47:1014-21.

16. Bradley MB. The effect of participating in a functional electrical stimulation exercise program on affect in people with spinal cord injuries. Arch Phys Med Rehabil 1994;75:676-9.

17. Guest RS, Klose KJ, Needham-Shropshire BM, Jacobs PL. Evaluation of a training program for persons with SCI paraplegia using the Parastep® 1 ambulation system: part 4. Effect on physical selfconcept and depression. Arch Phys Med Rehabil 1997;78:804-7.

18. Carraro U. Italian contributions toward a RISE-2 european clinical trial: 1st organization meeting, Padua, February 13, 2008. Basic Appl Myol 2008;18:83-8.

19. Kern H, Stramare R, Martino L, et al. Permanent LMN denervation of human skeletal muscle and recovery by h-b FES: management and monitoring. Eur J Transl Myol 2010; 1:91-104.
20. Edmunds KJ, Árnadóttir Í, Gíslason $\mathrm{MK}$, et al. Nonlinear Trimodal Regression Analysis of Radiodensitometric Distributions to Quantify Sarcopenic and Sequelae Muscle Degeneration.

21. Comput Math Methods Med 2016;2016:8932950. doi: 10.1155/2016/8932950. Epub 2016 Dec 27.

22. Coste CA, Mayr W, Bijak M, et al. FES in Europe and Beyond: Current Translational Research. Eur J Transl Myol 2016 Dec 16;26(4):6369. doi: 10.4081/ejtm.2016.6369. eCollection 2016 Sep 15.

23. Carraro U, Kern H, Gava P, et al. Recovery from muscle weakness by exercise and FES: lessons from Masters, active or sedentary seniors and SCI patients. Aging Clin Exp Res 2016 Sep 3. [Epub ahead of print] Review.

24. Carraro U. 2017Spring PaduaMuscleDays, roots and byproducts. Eur J Transl Myol 2017;27:6810. doi: 10.4081/ejtm.2017.6810. eCollection 2017 Jun 24 .

25. Kern H, Hofer C, Loefler S, et al. Atrophy, ultrastructural disorders, severe atrophy and degeneration of denervated human muscle in SCI and Aging. Implications for their recovery by Functional Electrical Stimulation, updated 2017. Neurol Res 2017 Jul;39(7):660-666. doi: 10.1080/01616412.2017.1314906. Epub 2017 Apr 13. 